This item was submitted to Loughborough's Research Repository by the author.

Items in Figshare are protected by copyright, with all rights reserved, unless otherwise indicated.

\title{
Novel and engaging versus boring and stagnating: how do pupils and teachers alike perceive the state of creativity in secondary schools?
}

PLEASE CITE THE PUBLISHED VERSION

http://www.inter-disciplinary.net/publishing/id-press/ebooks/

\section{PUBLISHER}

(C) Inter-Disciplinary Press

\section{VERSION}

AM (Accepted Manuscript)

\section{PUBLISHER STATEMENT}

This work is made available according to the conditions of the Creative Commons Attribution-NonCommercialNoDerivatives 4.0 International (CC BY-NC-ND 4.0) licence. Full details of this licence are available at: https://creativecommons.org/licenses/by-nc-nd/4.0/

\section{LICENCE}

CC BY-NC-ND 4.0

\section{REPOSITORY RECORD}

Turner, Sarah. 2019. "Novel and Engaging Versus Boring and Stagnating: How Do Pupils and Teachers Alike Perceive the State of Creativity in Secondary Schools?". figshare. https://hdl.handle.net/2134/10248. 
This item was submitted to Loughborough's Institutional Repository (https://dspace.lboro.ac.uk/) by the author and is made available under the following Creative Commons Licence conditions.

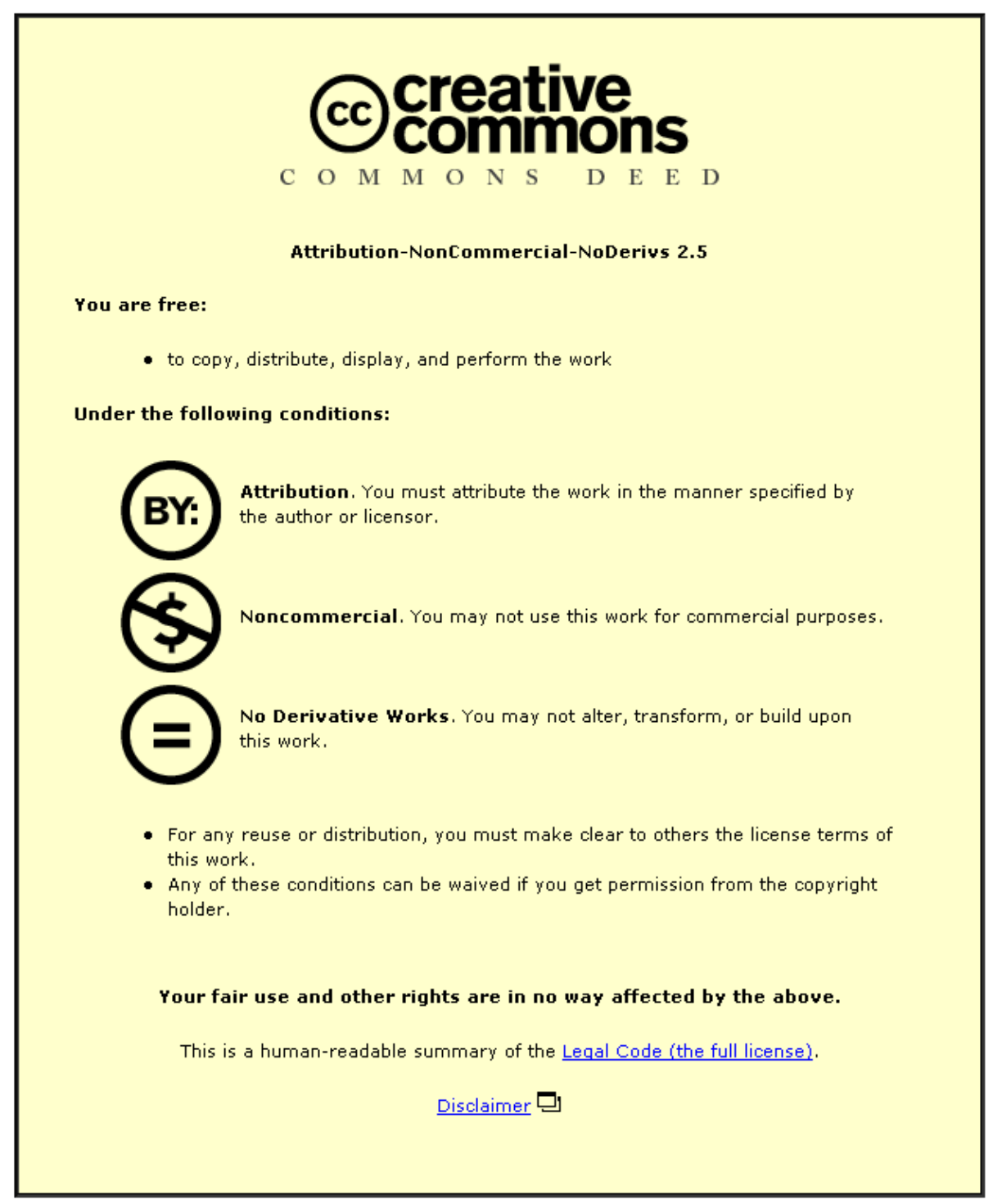

For the full text of this licence, please go to: http://creativecommons.org/licenses/by-nc-nd/2.5/ 


\title{
Novel and Engaging versus Boring and Stagnating: How do pupils and teachers alike perceive the state of creativity in secondary schools?
}

\author{
S. Turner Loughborough University S.Turner4@lboro.ac.uk
}

\section{Introduction}

Creativity means 'thinking outside of the box but sensibly' (Yr 7 girl).

Inspiring pupils with original ideas and tasks in their lessons can be paramount to engaging them. Once engaged, pupils are more likely to enjoy learning and achieve their full potential, be motivated and not misbehave. For teachers to devise varied and novel tasks in their lessons requires thought and preparation, and can present significant challenges. 'Creativity' is a complex concept, involving different aspects of creative teaching and learning (Simmons and Thompson, 2008).

This paper reports on a case study that was undertaken to investigate how teachers in England interpret and deliver 'creative teaching' at Key Stage 3 (KS3) (11-14yrs) and how pupils respond to such teaching styles. Lesson observations, teacher questionnaires and pupil interviews were carried out and the results were analysed.

\section{Relevant Literature}

The importance and relevance of pupils being creative at school, and acquiring surrounding skills, is highlighted in the revised National Curriculum 2008 for KS3. The National Curriculum states that:

'Creativity involves the use of imagination and intellect to generate ideas...experiencing the wonder and inspiration of human ingenuity and achievement...can spark individual enthusiasms that contribute to personal fulfilment' (QCA, 2008).

Today's society provides pupils with the opportunity of aspiring to a host of possible careers. Therefore it is the responsibility of the education system to equip pupils with the necessary skills to be able to be flexible, to think independently and to work with others. Pupils also require confidence to be able to work in changing times and adapt to working in the twenty first century.

Creativity can, and should, be applied to all school subjects even though it is often more commonly associated with arts subjects such as drama, music and art (McWilliam and Haukka, 2008). The misconception that creativity is the prerogative of arts subjects is a concern as it denies the place of creative teaching in science and mathematics. Creative teaching can manifest itself differently in each school subject and 'should permeate the curriculum and the life of the school' (QCA, 2008). 
Creativity can be more often associated with primary school teaching than secondary school teaching. However, to engage older pupils and help them retain information, learn key skills and enjoy lessons, there is a role for creativity at secondary school. All pupils have the capacity to be creative (QCA, 2008) and this will exhibit itself slightly differently in each pupil; it could be a flair for creative writing, poems, songs, thinking, questioning, drawing, creating an experiment, tackling a calculation or expressing themselves in sport. Allowing pupils to explore a topic in their own way may result in the creation of something original. It also allows pupils to create something themselves which is often the most effective way of learning; once something new is created, either entirely new or simply new to that pupil, the pupil has ownership and understanding which is deep-rooted and permanent. As Pagano comments,

'In order for a child to understand something, he must construct it himself; he must re-invent it' (Pagano, 1979, p. 137).

However, for some pupils this is extremely difficult and they may initially express anxiety towards working in this way. While the Higher Order Thinking Skills (Bloom's taxonomy,1956; Anderson and Krathwohl, 2001) places 'creativity' as the highest order thinking skill, to expect all pupils to work and think at this level, which is the most difficult, is unreasonable. Yet, with guidance and patience some pupils may develop their confidence working in this area.

Having discussed the significance of pupil engagement, pupil learning and skills developed for future employment, this paper will ask why creativity is often not prominent in all subjects and often not employed for the benefit of pupils by teachers in their lessons. First of all, consideration must be made of the term 'creativity' which is complex and difficult to define. Definitions incorporate many different words - such as novel, original, inventive or imaginative and link to producing something that has never been achieved before. However, does this creation simply have to be novel to the pupil/teacher or completely new? Using their imagination, some pupils can move completely away from the focus and is this useful? A simpler interpretation, with clear guidelines, basing creativity in terms of four key characteristics, is provided by the National Advisory Committee on Creative and Cultural Education (NACCCE):

'First, they [the characteristics of creativity] always involve thinking or behaving imaginatively. Second, overall this imaginative activity is purposeful: that is, it is directed to achieving an objective. Third, these processes must generate something original. Fourth, the outcome must be of value in relation to the objective' (NACCCE, 1999, p. 29).

Creativity is often a word that can cause apprehension for some teachers because it suggests time is required to consider and develop creative resources and already, 
'...teachers are under high levels of pressure and are overburdened with excessive workloads.' (Simmons and Thompson, 2008, p. 612)

Some teachers may lack confidence in their own creative ability and feel they do not possess creative attributes themselves. They may therefore find it difficult to approach creative ideas and subsequently do not encourage their pupils to be creative. Moreover, curriculum constraints do not allow time for pupils to engage in creative projects. However, being creative could come about in normal classroom activities such as question and answer sessions or the way in which a pupil approaches a written task or poster.

Teachers may misunderstand creativity and feel they will lose classroom control if they adopt a creative classroom. As Robinson has pointed out,

'...[a] misconception is that creativity is to do with free expression. This is partly why there's such concern about creativity in education. Critics think of children running wild and knocking down the furniture: with being spontaneous and uninhibited rather than with serious academic work' (Robinson, 2001, p. 113).

Teachers may require training to help them appreciate that creativity need not involve a loss of control, and that they would benefit from sharing methods of devising creative tasks. Lack of training in creative teaching may also affect some teachers' confidence. In particular, this could be an issue with many experienced teachers; it could be a daunting task if they are expected to do something unfamiliar to them, and having heard the theory, they may lack confidence in putting the ideas into practice (Treffinger et al., 1968).

Amidst the complexities involved with defining creativity and the difficulties impacting on some teachers, there are benefits, which have been highlighted in this paper, for incorporating creativity at secondary schools.

\section{Research Questions}

In investigating creativity within the classroom, this study will centre on two key research questions:

$1 \quad$ How do teachers interpret creativity within their KS3 teaching?

2 How do pupils respond to different activities within the classroom?

\section{Methodology}

A case study was undertaken with a school in the North of England to investigate 'creative teaching' across Key Stage 3. Willing teachers participated in a questionnaire and permitted their lessons to be observed and different age groups of pupils took part in small group semi-structured interviews. Drawing on between-methods triangulation (Brown and Dowling, 1998), more than one methodology was used to enable the formation of robust conclusions.

A sample of eleven teachers completed a 'Your Teaching Style' questionnaire (Soh, 2000). The questionnaire was voluntary amongst the staff and was non- 
subject specific. It was based on Cropley's (1997) nine-point list on fostering teachers' classroom behaviour:

1 encouraging pupils to learn independently (dependence);

2 having a co-operative, socially integrative style of teaching (integration);

3 motivating their pupils (motivation);

$4 \quad$ delaying judging pupils' ideas until they have been thoroughly worked through and clearly formulated (judgement);

$5 \quad$ encouraging flexible thinking (flexibility);

6 promoting self-evaluation in pupils (evaluation);

7 taking pupils' suggestions and questions seriously (question);

8 offering pupils opportunities to work with a wide variety of materials and under different conditions (opportunities);

9 helping pupils to learn to cope with frustration and failure (frustration).

There were 45 questions, covering the above nine points equally. The scoring for each statement ranged from 6 - all the time to 1- never. This particular questionnaire was selected for use as it addresses a variety of contexts for the use of creativity in the classroom and requires the teacher to consider their personal teaching style.

Ten teachers (drawn from a sample of approximately sixty) were observed across a range of KS3 subjects using the behaviour category form (Furman, 1998). This was selected as it was a suitable template to use for observing creative tasks and the different teacher behaviours being categorised helped the researcher. The teachers were informed that the observations would focus on aspects of creativity within the lesson and in response to this, without being asked by the researcher, teachers planned a creative lesson in line with how they interpreted the term.

A sample of four pupils (approximately 700 pupils in the school) from each age group participated in small group semi-structured interviews which had a list of predetermined questions. However, care was taken to maintain flexibility and a 'conversational style' approach throughout (Drever, 1997) to allow a comfortable atmosphere to ensure that pupils felt their responses were being listened to and considered useful and important. The questions asked were:

1) Which subjects do you think enable you to be creative?

2) Do creative tasks help you to learn?

3) What do you understand by the term 'creativity'?

\section{Results}

The two statistical approaches used to analyse the results were the mean and the standard deviation. The mean was selected because the researcher was observing the distribution of teacher scores from the questionnaire and requiring information on the central tendency (Cohen and Holliday, 1982). The 
standard deviation provided information on the 'individual deviations from the mean of the distribution' (Phillips, 2000, p.39).

When analysing the questionnaires, the mean was calculated for:

1) each teacher in each of the nine themes;

2) the overall mean for each theme of all the teachers.

In addition, for each theme, and for each individual teacher, the standard deviation was calculated. Since each theme of questions was similar the standard deviation should be low, showing no spread in their responses. However, for many of the individual teachers, there was a spread in each theme with their responses reflecting their own unease and variability in their ability to be creative and to encourage creativity in the classroom.

The results from the questionnaires showed that the highest means of activities/teacher behaviours undertaken in lessons were employing a cooperative, socially integrative style of teaching (integration), taking pupils' suggestions and questions seriously (question) and offering pupils opportunities to work with a variety of materials and under different conditions (opportunities). In the sample of teachers, one teacher consistently answered ' 6 ' (all the time) for each of the questions in the five questions revolving around questioning. Another teacher was also consistent with a '4' for each of these questions. The questions surrounding 'integration' saw three teachers each having low standard deviations $(0.45-0.55)$ for their answers which strengthens their use of this approach in their teaching. The responses for the 'opportunities' questions also showed one teacher being consistent in their approach, however, all teachers except one, answered a 5 or 6 to the question 'allow students to go beyond what I teach them'. This is encouraging as it suggests that pupils are encouraged to think and work independently. These results show that teachers perceive themselves as being able to listen to their pupils, encourage pupils to work in groups and inspire their pupils to do different things with what they have learnt. This self-perception by the teachers was observed by the researcher during the lesson observations providing further evidence.

The lowest means were in encouraging pupils to learn independently (dependence), delaying judging pupils' ideas until they have been thoroughly worked through and clearly formulated (judgement) and promoting selfevaluation in pupils (evaluation). One question in 'dependence' - 'teach students the basics and leave them to find out more' - had considerable variance (standard deviation of 1.27), demonstrating that teachers respond to this differently in their different subjects. This was also apparent in two other questions: one in the 'judgement' section ('do not give my own view immediately on students' ideas') which showed a standard deviation of 1.41 (responses varied from 1-6); and one question in the 'evaluation' section ('allow students to show one another their work before submission') which showed a standard deviation of 1.49. This suggests that teachers do not frequently use open-ended questions or allow pupils to develop their own thoughts or explore a concept/ topic on their own (Figure 1: Bar Chart of results). 
Since teachers had been advised that creativity was the research theme, all of the lessons observed contained a kind of creative task to be explored by the pupils. For example:

Create a menu (ICT)

Encouraging mnemonics, use of picture cards and games on smart board (French)

Investigative practical (physics)

Designing generally (design and technology)

Colour coding maps (geography)

Trip outside to find inspiration for writing (English)

Poster for wall to explain a scenario (mathematics)

Discussion (religious studies

These examples clearly illustrate the variation in how teachers respond to the term 'creativity'. The pupils clearly enjoyed the activities that were being undertaken and enjoyed being creative in the classroom. It was good to hear many positive and engaging discussions by the pupils and in many classrooms, there was a definite 'buzz' in the atmosphere.

The activities covered most often in the ten lessons observed were:

- the teacher giving instructions (often to explain the creative tasks outlined above);

- pupils having time to complete independent work;

- teachers giving praise and encouragement to the pupils during their tasks and throughout the lesson.

Comparing individual subjects, the tasks carried out in French, design and technology and mathematics had the most variety in teacher activities. Pupil activities were also varied in these lessons. However, in religious studies, ICT, biology, geography and physics the majority of the teacher activities were a general instruction and then the pupil completed the set activity. The tasks being completed by the pupils were of a divergent nature and therefore used the same category throughout the lesson.

\section{Pupil Interviews}

Pupils in each age group were responsive and engaging to talk to about creativity in their school lessons. The general consensus amongst the pupils was that they enjoyed creative lessons. Pupils in Yr 5 and 6 felt that subjects which promoted the use of creativity were: art, history, geography, music, ICT, sport and English. Similarly, pupils in Yrs 7,8 and 9 identified design and technology, art and geography as subjects involving the most creativity. Pupils in Yrs 7-9 also mentioned that science practicals helped them to remember content. Pupils in Yrs 10-11 felt that creativity was most evident in their option subjects: art, ICT, design and technology, music, physical education as well as in writing their English essays and discussion in religious studies. This age group felt creativity was not often required in mathematics or science lessons and that there was less demand for creative learning and creative activities in 
these lessons. They also expressed that as they have progressed through the school, they have experienced less creative teaching and learning. Games and creative tasks helped over half of the pupils in Yrs 7-9 to learn; only a small minority did not find these methods helpful. One pupil commented that they would like more creativity in mathematics because they find the subject hard.

Pupils' understanding of the term 'creativity' was quite inspiring and certainly expressed their intuitiveness and enthusiasm:

- expressing yourself

- making things

- using your imagination

- unique

- personal thought

Pupils in Yr 5 commented on their experience of science experiments and welcomed the fact that as they have moved up the school, the number of experiments carried out in lessons has increased. These pupils also remarked that they were more able to remember lessons that had been delivered in a creative manner and this year group enjoyed their school lessons.

Sixth form pupils considered creativity to be integral to how they use their time, enabling them to adapt to the needs of a situation at school. They felt the balance of their lessons was suitable though the demands in depth of knowledge from GCSE to A level had been difficult.

\section{Conclusions and Implications}

From the questionnaires, observations and pupil interviews there is evidence to show there are creative tasks carried out in many lessons. There are some subjects which appear to lend themselves to creativity more easily than others. All of the teachers had their pupils making or doing something. However, consideration as to whether following a teacher's instruction to make something and whether that is creative or not using the NACCCE definition as a guideline is in question. This case study has highlighted that teachers differ in their interpretations of the term 'creativity', and that it is applied to different teaching subjects in a variety of ways perhaps due to confusion of the term. Pupils' understanding of the term 'creativity' concurs with research of teachers' definitions of the term by Fryer and Collings (1991), using words such as imagination or original ideas.

It has also shown that pupils enjoy creative lessons and for some it helps them to remember and learn. This could improve pupils' attitudes towards certain subjects.

Creativity can be encouraged in questioning of pupils in class discussions as well as more novel approaches such as allowing debates, fun games, quizzes, art and projects. Another way in which creativity in teaching and learning can be developed is by employing the notion of an 'open 
environment' which supports pupils' ideas and emotions providing a feeling of safety; without this safety pupils may act in many different ways (Pagano, 1979) such as misbehaving or refusing to put in effort to complete the work. In this case study, teachers preferred to use closed style questioning. However, developing their use of open questioning may result in inspiring and encouraging pupils to question and think independently around solutions. While some teachers may find this daunting, it has the potential to be a rewarding and satisfying experience for both the pupil and the teacher, enabling them to explore a difficult and original question together. Creativity in this activity involves posing unique questions and explaining its relevance to the topic being taught. Combining these elements of creativity enables pupils to draw out more use than simply reciting facts in classroom discussions (Beghetto, 2007). This may provoke a deeper level of thinking in some pupils, enabling them to exercise their originality and independent thought (Beghetto, op. cit.). From the lesson observations, although there was quite a high percentage for 'divergent questions and tasks', these were linked to the activities being set and not to the questions in discussions; questions tended to be asked of a closed nature. This could be due to maintaining pace and allowing pupils to have more time to complete the set tasks.

Teachers show different responses to creativity within their classroom. There appears to be some confusion as to which activities can be classed as creative and there are stark differences between subjects; arts subjects such as English, drama, art and design and technology were more likely to involve some imaginative and novel work. Research by Fryer and Collings (1991) reported that teachers of mathematics, science, technology perceived creativity in impersonal or 'objective' terms. This is in contrast to teachers of English and creative arts subjects who interpreted creativity in more personal terms. This concurs with the observations and the types of activities undertaken; compare for instance, designing an experiment in science with a walk outside to gain inspiration for poetry in English. In the lessons observed, there was evidence of science and mathematics lessons with creative tasks but comments from the pupils show that this is perhaps more infrequent than common in practice. However, using a broad definition of the word allows creativity to be related to more than just one type of activity; it can be explored in each interaction with individual pupils through questioning or thinking.

Classroom conditions which have been shown to enhance a pupil's creativity are:

- rewarding creative thinking

- teaching tolerance towards new ideas or supporting initiative

- developing skills to criticize

- creating problem situations

- enhancing creative atmosphere

(Torrance, 1964)

These are helpful suggestions for teachers and may provide a starting point for some in teaching creatively for the first time or to help other teachers develop their use of creativity even further. 
The challenge is to encourage teachers who fear being more creative, due to it being an additional workload or losing classroom control, to not be afraid to explore any opportunity for creative teaching within the classroom. Teachers should be excited by enhancing pupils' thirst for knowledge and engaging with them, and helping them, to progress and further their understanding. A recommendation could be providing teaching and guidance to trainee teachers in the diverse nature of creativity and how it can be applied in the classroom; this may increase the quantity and quality of creative teaching.

Educating teachers that creativity relates to: teaching creatively, teaching for creativity and creative learning (NACCCE, 1999) is imperative so that all areas are explored. Teaching creatively requires teachers being inspiring, stimulating curiosity, knowing their subject well yet also continuing to learn (Fautley and Savage, 2007). Many of these attributes teachers possess but perhaps do not recognise as being creative. Importantly, all teachers have the skills of being creative (Longshaw, 2009); often all that is required is to have the confidence to try and a willingness to develop their own creative ability. As NACCCE points out,

'Teaching for creativity involves teaching creatively. Young people's creative abilities are most likely to be developed in an atmosphere in which the teacher's creative abilities are properly engaged. To put it another way, teachers cannot develop the creative abilities of their pupils if their own creative abilities are suppressed' (NACCCE, 1999, p. 90).

Within the classroom, the four key elements that could enable pupils to engage and experience creative learning in lessons, to be inspired to learn, are:

- Divergent thinking - develop pupils' imagination;

- Experiential learning - developing and accumulating pupils' own learning experiences;

- Motivation - fostering an on-task mentality where pupils want to engage and learn and explore ideas;

- Enjoyment - creative learning should be fun! (Fautley and Savage, 2007, p. 55).

If teachers can foster this creative learning atmosphere, and pupils respond positively, our hope would be that pupils will enjoy their school lessons.

Creative learning has the capacity to raise pupils' expectations of themselves and their learning. Pupils' enthusiasm towards learning, leading to an enjoyment of exploring topics being taught in original and novel ways, could enable both teachers and pupils to blossom and enjoy the learning experience together.

One final pupil thought on inspiring teachers to engage with creative teaching and the impact on their pupils:

Creativity: 'would like it in all subjects but not necessarily in every lesson' (Yr 9 boy). 


\section{References}

Anderson, L.W. and Krathwohl, D.R. (2001) A taxonomy for learning, teaching and assessing: a revision of Bloom's taxonomy of educational objectives. London: Longman.

Bloom, B.S. (1956) Taxonomy of educational objectives. Handbook I: the cognitive domain. New York: David McKay.

Beghetto, R.A. (2007) Does creativity have a place in classroom discussions? Prospective teachers' response preferences. Thinking Skills and Creativity, 2(1), 1-9.

Cohen, L. and Holliday, M. (1982) Statistics for Social Scientists. London: Harper and Row.

Drever, E. (1997) Using Semi-Structured Interviews in Small Scale Research: A Teacher's Guide. Glasgow: SCRE Publications.

Fautley, M. and Savage, J. (2007) Creativity in Secondary Education. Exeter: Learning Matters.

Fryer, M. and Collings, J.A. (1991) British Teachers' Views of Creativity. Journal of Creative Behavior, 25(1), 75-81.

Furman, A. (1998) Teacher and Pupil Characteristics in the Perception of the Creativity of Classroom Climate. Journal of Creative Behavior, 32(4), 258-277.

Longshaw, S. (2009) Creativity in science teaching. School Science Review, 90(332), 91-94.

McWilliam, E. and Haukka, S. (2008) Educating the creative workforce: new directions for twenty-first century schooling. British Educational Research Journal, 34(5), 651-666.

NACCCE (1999) All our futures: creativity, culture and education. Sudbury, Suffolk: DfEE.

QCA (2004) Available at: http://www.qca.org.uk/14-19/higher-

education/index.htm [accessed 2.8.08].

QCA (2008) National Curriculum. Available at:

http://curriculum.qca.org.uk/key-stages-3-and-4/cross-curriculumdimensions/creativitycriticalthinking/index.aspx [accessed 28.5.09].

Pagano, A. (1979) Learning and Creativity. Journal of Creative Behavior, 13(2), 127-138.

Phillips, J.L. (2000) How to think about statistics. Sixth Edition. Basingstoke: W.H. Freeman and Company. 
Robinson, K. (2001) Out of our minds: learning to be creative. Oxford: Capstone.

Simmons, R. and Thompson, R. (2008) Creativity and performativity: the case of further education. British Educational Research Journal, 34(5), 601-618.

Soh, K. (2000) Indexing Creativity Fostering Teacher Behavior: A Preliminary Validation Study. Journal of Creative Behavior, 34(2), 118-134.

Treffinger, D., Ripple, R.E. and Dacey, J.S. (1968) Teachers' Attitudes About Creativity. Journal of Creative Behavior, 2(4), 242-248.

\section{Figure 1}

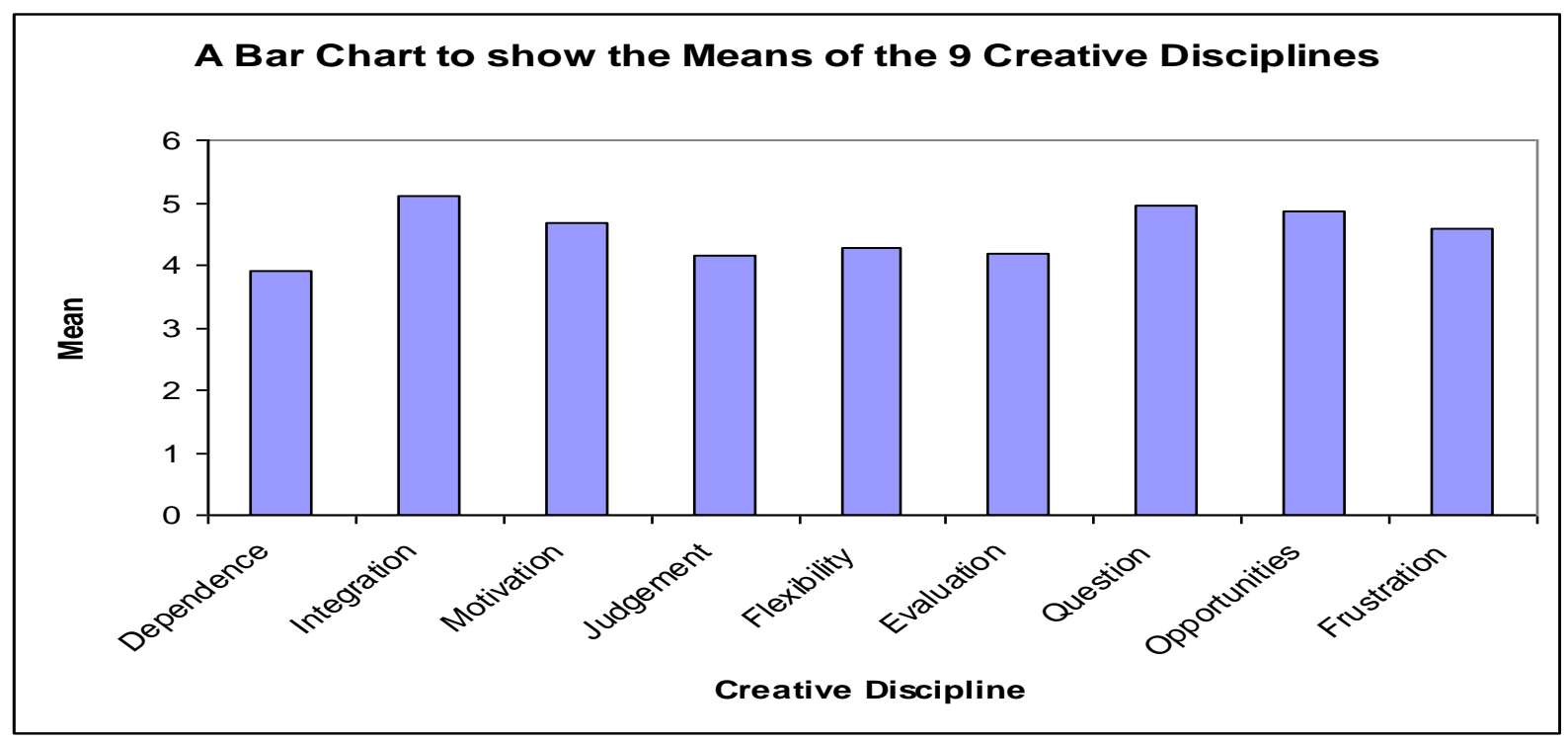

Figure 1: A Bar Chart to show the Means for each Theme of Questions on the Questionnaire 